Jurnal Inkofar * Volume 1 No. 1 Juli 2019 * ISSN: 2615-3645 (Print) / 2581-2920 (Online)

Tersedia secara online di: http://www.politeknikmeta.ac.id/meta/ojs/

\title{
EVALUASI STANDAR PELAYANAN KEFARMASIAN APOTEK DI APOTEK X BERDASARKAN PERMENKES NOMOR 73 TAHUN 2016
}

\author{
Tisa Amalia ${ }^{1}$ \\ ${ }^{1}$ Program Studi Farmasi / Politeknik META Industri Cikarang / tisa@politeknikmeta.ac.id
}

\begin{abstract}
Pharmacists must understand and be aware of the possibility of medication errors in the service process and identify, prevent and resolve drug-related problems, pharmacoeconomic problems, and social pharmacy. Avoiding this, a pharmacist must practice according to pharmaceutical service standards. This study aims to determine the application of the Standard Pharmaceutical Services at the X City Pharmacy Bandung.This study uses a normative juridical approach to research methods, namely by reviewing or analyzing secondary data in the form of legal materials, especially primary legal materials and secondary legal materials by understanding the law as a set of rules or positive norms in the legal system that regulating human life and supported by reality in the field. Besides using secondary data, it also uses primary data. Primary data is data obtained from the field by giving a questionnaire. The results of this study are that the Pharmacy $X$ has not all implemented pharmaceutical service standards that have been determined in the legislation. Pharmaceutical Service Standards In the management of pharmaceutical preparations, medical devices and medical materials are used up, prescription destruction has not been carried out every 5 years. Clinical pharmacy services in prescription studies do not take clinical consideration regarding unwanted drug reactions, contraindications and clinical considerations regarding interactions. Drug information services related to drug interaction information and pharmacokinetic information have not been carried out. In counseling activities documented counseling is not carried out. Pharmacy services at home, Monitoring of Drug Therapy and Monitoring of Side Effects Medication is not carried out.

Keywords: Standard Evaluation of Pharmaceutical Services, Pharmacy X, Minister of Health Regulation Number 73 of 2016
\end{abstract}

\begin{abstract}
ABSTRAK
Apoteker harus memahami dan menyadari kemungkinan terjadinya kesalahan pengobatan dalam proses pelayanan dan mengidentifikasi, mencegah serta mengatasi masalah terkait obat, masalah farmakoekonomi, dan farmasi sosial. Menghindari hal tersebut maka seorang apoteker harus menjalankan praktik sesuai dengan standar pelayanan kefarmasian. Penelitian ini bertujuan untuk mengetahui penerapan Standar Pelayanan Kefarmasian Di Apotek X Kota Bandung. Penelitian ini menggunakan metode penelitian pendekatan yang bersifat yuridis normatif, yaitu dengan mengkaji atau menganalisa data sekunder yang berupa bahan-bahan hukum terutama bahan hukum primer dan bahan hukum sekunder dengan memahami hukum sebagai seperangkat peraturan atau norma-norma positif di dalam sistem perundang-undangan yang mengatur mengenai kehidupan manusia dan didukung dengan kenyataan di lapangan. Selain menggunakan data sekunder, menggunakan juga data primer. Data primer adalah data yang diperoleh dari lapangan dengan cara memberikan kuesioner. Hasil dari penelitian ini yaitu bahwa Apotek X belum semuanya menerapkan standar pelayanan kefarmasian yang sudah ditentukan dalam peraturan perundang-undangan. Standar Pelayanan Kefarmasian Pada kegiatan pengelolaan sediaan farmasi, alat kesehatan dan bahan medis habis pakai belum dilakukan pemusnahan resep setiap 5 tahun. Pelayanan farmasi klinis pada pengkajian resep tidak dilakukan pertimbangan klinis terkait reaksi obat yang tidak diinginkan, kontraindikasi dan pertimbangan klinis terkait interaksi. Pelayanan informasi obat terkait informasi interaksi obat dan informasi farmakokinetik juga belum dilakukan. Pada kegiatan konselin tidak dilakukan konseling yang terdokumentasi. Pelayanan kefarmasian di rumah, Pemantauan Terapi Obat dan Monitoring Efek Samping Obat tidak dilakukan.
\end{abstract}

Kata Kunci: Evaluasi Standar Pelayanan Kefarmasian, Apotek X, Permenkes RI Nomor 73 Tahun 2016 


\section{PENDAHULUAN}

Upaya Kesehatan adalah setiap kegiatan untuk memelihara dan meningkatkan kesehatan dan tempat yang digunakan untuk menyelenggarakannya disebut sarana kesehatan. Sarana kesehatan berfungsi untuk melakukan upaya kesehatan dasar atau upaya kesehatan rujukan dan/atau upaya kesehatan penunjang. Selain itu, sarana kesehatan dapat juga dipergunakan untuk kepentingan pendidikan dan pelatihan serta penelitian, pengembangan ilmu pengetahuan dan teknologi di bidang kesehatan. Sesuai dengan uraian di atas, sarana kesehatan meliputi balai pengobatan, pusat kesehatan masyarakat (Puskesmas), rumah sakit umum,rumah sakit khusus,praktik dokter, praktik dokter gigi, praktik dokter spesialis, praktik dokter gigi spesialis, praktik bidan, toko obat, apotek, instalasi farmasi rumah sakit,pedagang besar farmasi, pabrik obat dan bahan obat,laboratorium kesehatan, sekolah dan akademi kesehatan, balai pelatihan kesehatan dan sarana kesehatan lainnya ( Charles, 2003 ).

Menurut Peraturan Menteri Kesehatan No 9 Tahun 2017 Tentang Apotek, Apotek adalah sarana pelayanan kefarmasian tempat dilakukan praktek kefarmasian oleh apoteker. Sebuah apotek harus dikelola oleh seorang apoteker yang professional agar dapat memberikan pelayanan kefarmasian yang professional. Pelayanan kefarmasian adalah suatu pelayanan langsung dan bertanggung jawab kepada pasien yang berkaitan dengan maksud mencapai hasil yang pasti untuk meningkatkan mutu kehidupan pasien (Satibi dkk, 2018).

Apoteker harus memahami dan menyadari kemungkinan terjadinya kesalahan pengobatan dalam proses pelayanan dan mengidentifikasi, mencegah serta mengatasi masalah terkait obat, masalah farmakoekonomi, dan farmasi sosial. Menghindari hal tersebut maka seorang apoteker harus menjalankan praktik sesuai dengan standar pelayanan. Standar Pelayanan Kefarmasian Di Apotik yang terbaru menggunakan Standar Pelayanan Kefarmasian Nomor 73 Tahun 2016 (Menkes, 2017).

Beberapa penelitian yang sudah dilakukan sebelumnya mengenai standar pelayanan kefarmasian di apotik dibeberapa kota menggunakan aturan Permenkes Nomor 35 Tahun 2014 Tentang Standar Pelayanan Kefarmasian Di Apotek. Berdasarkan penelitian-penelitian tersebut menunjukkan bahwa pelayanan kefarmasian yang dilakukan masih dalam kategori kurang memenuhi standar yang telah ditentukan (Sari, 2018).

Memperhatikan latar belakang masalah tersebut di atas maka dalam pembahasan mengenai materi dan substansi penelitian ini penulis memusatkan dan membatasi pembahasannya pada Bagaimana Standar Pelayanan Kefarmasian Di Apotek X di Kota Bandung.

\section{METODE PENELITIAN}

Penelitian Evaluasi Standar Pelayanan Kefarmasian Di Apotek X Kota Bandung menggunakan pendekatan yang bersifat yuridis normatif, yaitu dengan mengkaji data sekunder yang berupa bahanbahan hukum terutama bahan hukum primer yang berupa peraturan perundang-undangan dan bahan hukum sekunder berupa kuesioner dengan memahami hukum sebagai seperangkat peraturan atau norma-norma positif di dalam sistem perundang-undangan yang mengatur mengenai kehidupan manusia dan didukung dengan kenyataan di lapangan. Selain menggunakan data sekunder, menggunakan juga data primer. Data primer adalah data yang diperoleh dari lapangan dengan cara memberikan kuesioner. Acuan dari pertanyaan yang ada di kuesioner adalah Permenkes Nomor 73 Tahun 2016.

\section{HASIL ANALISA DATA DAN PEMBAHASAN}

\subsection{Karakteristik Responden}

Menurut Peraturan Pemerintah Republik Indonesia Nomor 51 Tahun 2009 Tentang Pekerjaan Kefarmasian menyebutkan bahwa tenaga kefarmasiaan adalah tenaga yang melakukan pekerjaan kefarmasian, yang terdiri atas Apoteker dan Tenaga Teknis Kefarmasian. Pada Tabel 1 merupakan karakteristik responden dalam penelitian ini.

Tabel 1. Karakteristik Responden

\begin{tabular}{|c|c|l|}
\hline No & \multicolumn{1}{|c|}{ Pertanyaan } & \multicolumn{1}{c|}{ Jawaban } \\
\hline 1 & Berapakah umur anda? & a. $21-35$ th \\
& & b. $36-50$ th \\
& & c. $>50$ th \\
\hline
\end{tabular}




\begin{tabular}{|c|c|c|}
\hline 2 & Apakah posisi anda di apotek? & $\begin{array}{ll}\text { a. } & \text { APA } \\
\text { b. Apoteker Pendamping } \\
\text { c. Apoteker Pengganti } \\
\text { d. } & \text { Asisten Apoteker }\end{array}$ \\
\hline 3 & $\begin{array}{l}\text { Sudah berapa lama anda bekerja } \\
\text { di apotek yang sekarang? }\end{array}$ & $\begin{array}{l}\text { a. }<1 \text { th } \\
\text { b. } \mathbf{1 - 5}^{\text {th }} \\
\text { c. } 6-10^{\text {th }} \\
\text { d. }>10^{\text {th }}\end{array}$ \\
\hline 4 & $\begin{array}{l}\text { Apakah anda memiliki } \\
\text { pekerjaan yang lain? }\end{array}$ & $\begin{array}{l}\text { a. Ya } \\
\text { b. Tidak }\end{array}$ \\
\hline 5 & $\begin{array}{l}\text { Berapa hari anda bekerja di } \\
\text { apotek yang sekarang? }\end{array}$ & $\begin{array}{l}\text { a. 1-3 hari } \\
\text { b. 3-5 hari } \\
\text { c. } 6-7 \text { hari }\end{array}$ \\
\hline 6 & $\begin{array}{l}\text { Berapa lama bekerja di apotek } \\
\text { dalam satu hari? }\end{array}$ & $\begin{array}{ll}\text { a. } & <4 \text { jam } \\
\text { b. } & \text { 4-6 jam } \\
\text { c. } & 6-8 \text { jam } \\
\text { d. } & >8 \text { jam }\end{array}$ \\
\hline 7 & $\begin{array}{l}\text { Apakah punya apoteker } \\
\text { pendamping? }\end{array}$ & $\begin{array}{ll}\text { a. } & \text { Tidak punya } \\
\text { b. } & \text { Punya }\end{array}$ \\
\hline
\end{tabular}

\subsection{Pengelolaan Sediaan Farmasi, Alat Kesehatan dan Bahan Medis Habis Pakai}

Berdasarkan Permenkes RI No 73 Tahun 2016 pasal 3 ayat 2 dikatakan bahwa Pengelolaan Sediaan Farmasi, Alat Kesehatan Dan Bahan Medis Habis Pakai meliputi perencanaan, pengadaan, penerimaan, penyimpanan, pemusnahan, pengendalian, pencataan dan pelaporan.

Pengelolaan sediaan farmasi, alat kesehatan dan bahan medis habis pakai dilakukan berdasarkan peraturan perundang-undangan yang berlaku. Pada Tabel 2 adalah kegiatan pengelolaan sediaan farmasi alat kesehatan dan bahan medis habis pakai di Apotik X.

Tabel 2. Pengelolaan Sediaan Farmasi, Alat Kesehatan dan Bahan Medis Habis Pakai

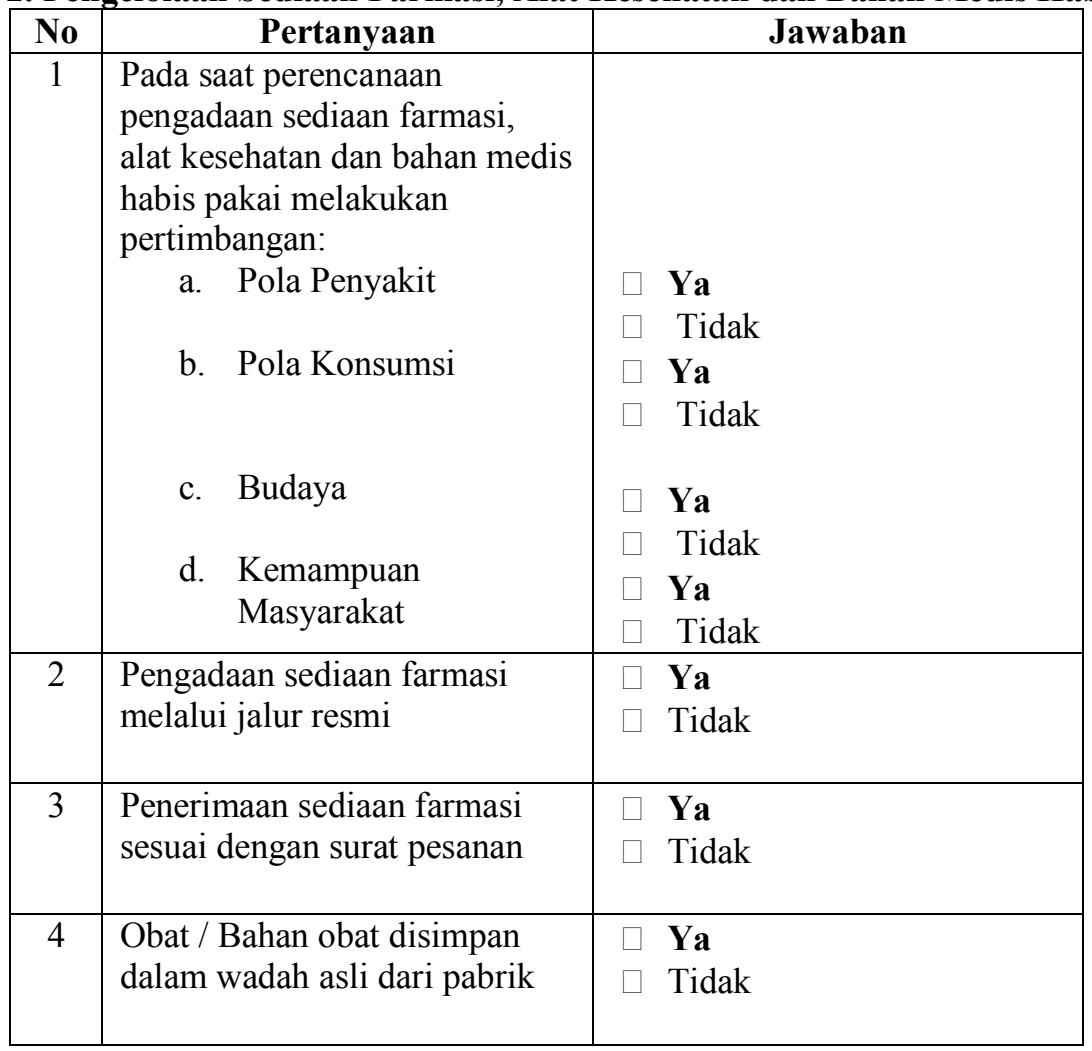




\begin{tabular}{|c|c|c|}
\hline 5 & $\begin{array}{l}\text { Semua obat/bahan obat } \\
\text { disimpan pada kondisi yang } \\
\text { sesuai }\end{array}$ & $\begin{array}{l}\square \text { Ya } \\
\square \text { Tidak }\end{array}$ \\
\hline 6 & $\begin{array}{l}\text { Tempat penyimpanan obat } \\
\text { tidak dipergunakan untuk } \\
\text { menyimpan barang lain }\end{array}$ & $\begin{array}{ll}\square \text { Ya } \\
\square \text { Tidak }\end{array}$ \\
\hline 7 & $\begin{array}{l}\text { Sistem penyimpanan dilakukan } \\
\text { dengan memperhatikan bentuk } \\
\text { sediaan dan kelas terapi obat } \\
\text { serta di susun secara alfabetis }\end{array}$ & $\begin{array}{ll}\square \text { Ya } \\
\square \text { Tidak }\end{array}$ \\
\hline 8 & $\begin{array}{l}\text { Pengeluaran obat memakai } \\
\text { sistem FEFO (First Expire } \\
\text { First Out) dan FIFO (First In } \\
\text { First Out) }\end{array}$ & $\begin{array}{ll}\square \text { Ya } \\
\square \text { Tidak }\end{array}$ \\
\hline 9 & $\begin{array}{l}\text { Obat Kadaluarsa atau rusak } \\
\text { dimusnahkan sesuai dengan } \\
\text { jenis dan bentuk sediaan }\end{array}$ & $\begin{array}{ll}\square \text { Ya } \\
\square \text { Tidak }\end{array}$ \\
\hline 10 & Pemusnahan resep setiap 5th & $\begin{array}{l}\text { Ya } \\
\square \text { Tidak } \\
\end{array}$ \\
\hline 11 & Pengendalian persedian obat & $\begin{array}{ll}\text { Ya } \\
\square \text { Tidak } \\
\end{array}$ \\
\hline 12 & $\begin{array}{l}\text { Pencatatan dilakukan pada } \\
\text { setiap proses pengelolaan } \\
\text { sediaan farmasi,alat kesehatan } \\
\text { dan bahan medis habis pakai }\end{array}$ & $\begin{array}{ll}\square \mathbf{Y a} \\
\square \text { Tidak }\end{array}$ \\
\hline 13 & $\begin{array}{l}\text { Pelaporan narkotika dan } \\
\text { psikotropika sesuai dengan } \\
\text { aturan perundang-undangan }\end{array}$ & $\begin{array}{l}\square \text { Ya } \\
\square \text { Tidak (tidak ada obat } \\
\text { tsb) }\end{array}$ \\
\hline 14 & Terdapat pelaporan internal & $\begin{array}{ll}\square & \text { Ya } \\
\square & \text { Tidak } \\
\end{array}$ \\
\hline
\end{tabular}

Berdasarkan hasil penelitian di atas didapatkan hasil yaitu untuk pengelolaan sediaan farmasi, alat kesehatan dan bahan medis habis pakai yang dilakukan oleh Apotik X sudah dilakukan berdasarkan peraturan perundang-undangan yang berlaku. Namun ada satu kegiatan yang belum dilakukan yaitu pemusnahan resep setiap 5 tahun.

Menurut Peraturan Menteri Kesehatan Republik Indonesia Nomor 9 Tahun 2017 tentang Apotek pasal 23 ayat 2 menyebutkan bahwa resep harus disimpan di Apotek dengan baik paling singkat 5 tahun.

\subsection{Pelayanan Farmasi Klinis}

Menurut Permenkes RI No 73 Tahun 2016 pasal 3 ayat 3 menyebutkan bahwa pelayanan farmasi klinis yang ada di apotik yaitu pengkajian resep, dispensing, pelayanan informasi obat (PIO), konseling, pelayanan kefarmasian di rumah, pemantauan terapi obat, monitoring efek samping obat.

Pelayanan farmasi klinik di Apotek merupakan bagian dari Pelayanan Kefarmasian yang langsung dan bertanggung jawab kepada pasien berkaitan dengan Sediaan Farmasi, Alat Kesehatan, dan Bahan Medis Habis Pakai dengan maksud mencapai hasil yang pasti untuk meningkatkan kualitas hidup pasien. Berikut adalah tabel 3 yang merupakan kegiatan pelayanan farmasi yang ada di apotik X. 
Tabel 3. Pelayanan Farmasi Klinis

\begin{tabular}{|c|c|c|c|c|}
\hline NO & Kegiatan & $\begin{array}{c}\text { Oleh } \\
\text { Apoteker }\end{array}$ & $\begin{array}{l}\text { Oleh Tenaga } \\
\text { Teknis } \\
\text { Kefarmasian }\end{array}$ & $\begin{array}{c}\text { Tidak } \\
\text { Dilakukan }\end{array}$ \\
\hline $\mathbf{A}$ & Pengkajian Resep & & & \\
\hline 1 & $\begin{array}{l}\text { Kajian administrasi: nama } \\
\text { pasien, umur, jenis } \\
\text { kelamin, dan berat badan }\end{array}$ & $\mathrm{V}$ & $\mathrm{v}$ & \\
\hline 2 & $\begin{array}{l}\text { Kajian administrasi: nama } \\
\text { dokter, nomor surat izin } \\
\text { praktek (SIP), alamat, } \\
\text { nomor telepon dan paraf }\end{array}$ & $\mathrm{V}$ & $\mathrm{v}$ & \\
\hline 3 & $\begin{array}{l}\text { Kajian administrasi: } \\
\text { tanggal penulisan resep }\end{array}$ & $\mathrm{v}$ & $\mathrm{V}$ & \\
\hline 4 & $\begin{array}{l}\text { Kajian kesesuaian } \\
\text { farmasetik: bentuk dan } \\
\text { kekuatan sediaan }\end{array}$ & $\mathrm{v}$ & $\mathrm{V}$ & \\
\hline 5 & $\begin{array}{l}\text { Kajian kesesuaian } \\
\text { farmasetik: stabilitas }\end{array}$ & $\mathrm{v}$ & $\mathrm{v}$ & \\
\hline 6 & $\begin{array}{l}\text { Kajian kesesuaian } \\
\text { farmasetik: ketercampuran } \\
\text { obat }\end{array}$ & $\mathrm{v}$ & $\mathrm{v}$ & \\
\hline 7 & $\begin{array}{l}\text { Pertimbangan klinis } \\
\text { terkait: ketepatan indikasi } \\
\text { dan dosis obat }\end{array}$ & $\mathrm{v}$ & $\mathrm{v}$ & \\
\hline 8 & $\begin{array}{l}\text { Pertimbangan klinis } \\
\text { terkait: aturan, cara dan } \\
\text { lama penggunaan obat }\end{array}$ & $\mathrm{V}$ & $\mathrm{v}$ & \\
\hline 9 & $\begin{array}{l}\text { Pertimbangan klinis } \\
\text { terkait: duplikasi dan/atau } \\
\text { polifarmasi }\end{array}$ & $\mathrm{V}$ & $\mathrm{v}$ & \\
\hline 10 & $\begin{array}{l}\text { Pertimbangan klinis } \\
\text { terkait: reaksi obat yang } \\
\text { tidak diinginkan (alergi, } \\
\text { efek samping obat, } \\
\text { manifestasi klinis lainnya) }\end{array}$ & & & $\mathrm{v}$ \\
\hline 11 & $\begin{array}{l}\text { Pertimbangan klinis } \\
\text { terkait: kontraindikasi }\end{array}$ & & & $\mathrm{v}$ \\
\hline 12 & $\begin{array}{l}\text { Pertimbangan klinis } \\
\text { terkait: interaksi }\end{array}$ & & & $\mathrm{v}$ \\
\hline $\mathbf{B}$ & Dispensing & & & \\
\hline 1 & $\begin{array}{l}\text { Menyiapkan obat sesuai } \\
\text { permintaan resep }\end{array}$ & $\mathrm{v}$ & $\mathrm{v}$ & \\
\hline 2 & Melakukan peracikan obat & & $\mathrm{v}$ & \\
\hline 3 & Memberikan etiket obat & $\mathrm{v}$ & $\mathrm{V}$ & \\
\hline 4 & $\begin{array}{l}\text { Memasukan obat ke dalam } \\
\text { wadah yang tepat dan } \\
\text { terpisah untuk obat yang } \\
\text { berbeda }\end{array}$ & $\mathrm{v}$ & $\mathrm{v}$ & \\
\hline 5 & $\begin{array}{l}\text { Memeriksa ulang obat } \\
\text { yang akan diserahkan }\end{array}$ & $\mathrm{v}$ & $\mathrm{v}$ & \\
\hline
\end{tabular}


Jurnal Inkofar * Volume 1 No. 1 Juli 2019 * ISSN: 2615-3645 (Print) / 2581-2920 (Online) Tersedia secara online di: http://www.politeknikmeta.ac.id/meta/ojs/

\begin{tabular}{|c|c|c|c|c|}
\hline $\mathbf{C}$ & $\begin{array}{l}\text { Pelayanan Informasi } \\
\text { Obat }\end{array}$ & & & \\
\hline 1 & $\begin{array}{l}\text { Memberikan informasi } \\
\text { kepada konsumen terkait: } \\
\text { dosis obat }\end{array}$ & $\mathrm{v}$ & $\mathrm{V}$ & \\
\hline 2 & $\begin{array}{l}\text { Memberikan informasi } \\
\text { kepada konsumen terkait: } \\
\text { bentuk sediaan }\end{array}$ & $\mathrm{v}$ & $\mathrm{v}$ & \\
\hline 3 & $\begin{array}{l}\text { Memberikan informasi } \\
\text { kepada konsumen terkait: } \\
\text { formulasi khusus }\end{array}$ & $\mathrm{v}$ & $\mathrm{v}$ & \\
\hline 4 & $\begin{array}{l}\text { Memberikan informasi } \\
\text { kepada konsumen terkait: } \\
\text { rute dan metode } \\
\text { pemberian }\end{array}$ & $\mathrm{v}$ & $\mathrm{v}$ & \\
\hline 5 & $\begin{array}{l}\text { Memberikan informasi } \\
\text { kepada konsumen terkait: } \\
\text { efek samping }\end{array}$ & $\mathrm{v}$ & $\mathrm{v}$ & \\
\hline 6 & $\begin{array}{l}\text { Memberikan informasi } \\
\text { kepada konsumen terkait: } \\
\text { interaksi obat }\end{array}$ & & & $\mathrm{V}$ \\
\hline 7 & $\begin{array}{l}\text { Memberikan informasi } \\
\text { kepada konsumen terkait: } \\
\text { harga }\end{array}$ & $\mathrm{v}$ & $\mathrm{v}$ & \\
\hline 8 & $\begin{array}{l}\text { Memberikan informasi } \\
\text { kepada konsumen terkait: } \\
\text { farmakokinetik }\end{array}$ & & & $\mathrm{V}$ \\
\hline 9 & $\begin{array}{l}\text { Memberikan informasi } \\
\text { kepada konsumen terkait: } \\
\text { farmakologi }\end{array}$ & $\mathrm{v}$ & & \\
\hline 10 & $\begin{array}{l}\text { Memberikan informasi } \\
\text { kepada konsumen terkait: } \\
\text { terapeutik dan alternatif }\end{array}$ & $\mathrm{v}$ & $\mathrm{v}$ & \\
\hline 11 & $\begin{array}{l}\text { Memberikan informasi } \\
\text { kepada konsumen terkait: } \\
\text { efikasi }\end{array}$ & $\mathrm{v}$ & & \\
\hline 12 & $\begin{array}{l}\text { Memberikan informasi } \\
\text { kepada konsumen terkait: } \\
\text { keamanan penggunaan } \\
\text { pada ibu hamil dan } \\
\text { menyusui }\end{array}$ & $\mathrm{v}$ & $\mathrm{V}$ & \\
\hline 13 & $\begin{array}{l}\text { Memberikan informasi } \\
\text { kepada konsumen terkait: } \\
\text { stabilitas }\end{array}$ & $\mathrm{v}$ & $\mathrm{V}$ & \\
\hline 14 & $\begin{array}{l}\text { Memberikan informasi } \\
\text { kepada konsumen terkait: } \\
\text { ketersediaan }\end{array}$ & $\mathrm{v}$ & $\mathrm{v}$ & \\
\hline D & Konseling & & & \\
\hline 1 & $\begin{array}{l}\text { Membuka komunikasi } \\
\text { antara apoteker dengan } \\
\text { pasien }\end{array}$ & $\mathrm{v}$ & & \\
\hline
\end{tabular}


Jurnal Inkofar * Volume 1 No. 1 Juli 2019 * ISSN: 2615-3645 (Print) / 2581-2920 (Online) Tersedia secara online di: http://www.politeknikmeta.ac.id/meta/ojs/

\begin{tabular}{|c|c|c|c|}
\hline 2 & $\begin{array}{l}\text { Menilai pemahaman } \\
\text { pasien tentang } \\
\text { penggunaan obat melalui } \\
\text { Three Prime Questions }\end{array}$ & $\mathrm{V}$ & \\
\hline 3 & $\begin{array}{l}\text { Menggali informasi lebih } \\
\text { lanjut dengan memberi } \\
\text { kesempatan kepada pasien } \\
\text { untuk mengekplorasi } \\
\text { penggunaan obat }\end{array}$ & $\mathrm{V}$ & \\
\hline 4 & $\begin{array}{l}\text { Memberikan penjelasan } \\
\text { kepada pasien untuk } \\
\text { menyelesaikan masalah } \\
\text { penggunaan obat }\end{array}$ & $\mathrm{v}$ & \\
\hline 5 & $\begin{array}{l}\text { Melakukan verifikasi } \\
\text { akhir untuk memastikan } \\
\text { pemahaman pasien }\end{array}$ & $\mathrm{V}$ & \\
\hline 6 & $\begin{array}{l}\text { Melakukan konseling } \\
\text { yang terdokumentasi }\end{array}$ & & $\mathrm{V}$ \\
\hline $\mathbf{E}$ & $\begin{array}{l}\text { Pelayanan Kefarmasian } \\
\text { Di Rumah }\end{array}$ & & \\
\hline 1 & $\begin{array}{l}\text { Penilaian/pencarian } \\
\text { masalah yang } \\
\text { berhubungan dengan } \\
\text { pengobatan }\end{array}$ & & $\mathrm{V}$ \\
\hline 2 & $\begin{array}{l}\text { Identifikasi kepatuhan } \\
\text { pasien }\end{array}$ & & $\mathrm{V}$ \\
\hline 3 & $\begin{array}{l}\text { Pendampingan } \\
\text { pengelolaan Obat dan/atau } \\
\text { alat kesehatan }\end{array}$ & & $\mathrm{V}$ \\
\hline 4 & $\begin{array}{l}\text { Konsultasi masalah obat } \\
\text { atau masalah kesehatan } \\
\text { secara umum }\end{array}$ & & $\mathrm{V}$ \\
\hline 5 & $\begin{array}{l}\text { Monitoring pelaksanaan, } \\
\text { efektifitas dan keamanan } \\
\text { penggunaan obat } \\
\text { berdasarkan catatan } \\
\text { pengobatan pasien }\end{array}$ & & $\mathrm{V}$ \\
\hline 6 & $\begin{array}{l}\text { Dokumentasi pelaksanaan } \\
\text { pelayanan kefarmasian di } \\
\text { rumah }\end{array}$ & & $\mathrm{V}$ \\
\hline $\mathbf{F}$ & $\begin{array}{l}\text { Pemantauan Terapi } \\
\text { Obat }\end{array}$ & & \\
\hline 1 & $\begin{array}{l}\text { Memilih pasien sesuai } \\
\text { dengan kriteria }\end{array}$ & & $\mathrm{V}$ \\
\hline 2 & $\begin{array}{l}\text { Mengambil data yang } \\
\text { dibutuhkan }\end{array}$ & & $\mathrm{V}$ \\
\hline 3 & $\begin{array}{l}\text { Melakukan identifikasi } \\
\text { masalah terkait obat }\end{array}$ & & $\mathrm{V}$ \\
\hline 4 & $\begin{array}{l}\text { Menentukan prioritas } \\
\text { masalah sesuai kondisi } \\
\text { pasien }\end{array}$ & & $\mathrm{V}$ \\
\hline 5 & $\begin{array}{l}\text { Memberikan rekomendasi } \\
\text { atau rencana tindak lanjut }\end{array}$ & & $\mathrm{V}$ \\
\hline
\end{tabular}


Jurnal Inkofar * Volume 1 No. 1 Juli 2019 * ISSN: 2615-3645 (Print) / 2581-2920 (Online)

Tersedia secara online di: http://www.politeknikmeta.ac.id/meta/ojs/

\begin{tabular}{|c|l|l|c|c|}
\hline 6 & $\begin{array}{l}\text { Hasil identifikasi masalah } \\
\text { terkait obat dan } \\
\text { rekomendasi yang telah } \\
\text { dibuat dikomunikasikan } \\
\text { kepada tenaga kesehatan } \\
\text { terkait }\end{array}$ & & $\mathrm{v}$ \\
\hline 7 & $\begin{array}{l}\text { Dokumentasi pelaksanaan } \\
\text { pemantauan terapi obat }\end{array}$ & & & $\mathrm{V}$ \\
\hline G & $\begin{array}{l}\text { Monitoring Efek } \\
\text { Samping Obat (MESO) }\end{array}$ & & & $\mathrm{V}$ \\
\hline 1 & $\begin{array}{l}\text { Mengidentifikasi obat dan } \\
\text { pasien yang mempunyai } \\
\text { resiko tinggi memiliki } \\
\text { efek samping obat }\end{array}$ & & & $\mathrm{v}$ \\
\hline 2 & Mengisi formulir MESO & & & $\mathrm{v}$ \\
\hline 3 & $\begin{array}{l}\text { Melaporkan ke pusat } \\
\text { MESO }\end{array}$ & & & \\
\hline
\end{tabular}

Berdasarkan hasil penelitian yang sudah dilakukan ada beberapa pelayanan farmasi klinik yang tidak dilakukan oleh Apotik X diantaranya yaitu:

a. Pada pengkajian resep tidak dilakukan pertimbangan klinis terkait reaksi obat yang tidak diinginkan (alergi, efek samping obat, manifestasi klinis lainnya), Pertimbangan klinis terkait kontraindikasi, Pertimbangan klinis terkait interaksi.

Pengkajian pertimbangan klinis terkait reaksi obat yang tidak diinginkan, kontraindikasi dan interaksi hendaknya dilakukan oleh seorang apoteker. Hal ini dimaksudkan supaya apabila terdapat ketidaksesuaian dari hasil pengkajian maka seorang apoteker dapat segera menghubungi dokter yang menuliskan resep tersebut.

b. Pada pelayanan informasi obat tidak dilakukan memberikan informasi kepada konsumen terkait interaksi obat, memberikan informasi kepada konsumen terkait farmakokinetik

Berdasarkan Undang Undang Kesehatan Nomor 36 Tahun 2009:

Pasal 7 menyebutkan bahwa setiap orang berhak untuk mendapatkan informasi dan edukasi tentang kesehatan yang seimbang dan bertanggung jawab

Pasal 8 menyebukan bahwa setiap orang berhak memperoleh informasi tentang data kesehatan dirinya termasuk tindakan dan pengobatan yang telah maupun yang akan diterimanya dari tenaga kesehatan.

c. Pada bagian konseling tidak dilakukan konseling yang terdokumentasi

Berdasarkan Permenkes RI No 73 Tahun 2016, Apoteker mendokumentasikan konseling dengan meminta tanda tangan pasien sebagai bukti bahwa pasien memahami informasi yang diberikan dalam konseling

d. Pelayanan kefarmasian di rumah, Pemantauan Terapi Obat dan Monitoring Efek Samping Obat tidak dilakukan.

Apoteker sebagai pemberi layanan diharapkan juga dapat melakukan pelayanan kefarmasian bersifat kunjungan rumah, khususnya untuk kelompok lansia dan pasien dengan pengobatan penyakit kronis lainnya.

Pemantauan Terapi Obat juga perlu dilakukan untuk memastikan bahwa seorang pasien mendapatkan terapi obat yang efektif dan terjangkau dengan memaksimalkan efikasi dan meminimalkan efek samping. Adapun kriteri pasien yang memerlukan pemantauan terapi obat yaitu anak-anak, lanjut usia, ibu hamil dan menyusui, pasien dengan penerima obat lebih dari 5 jenis, pasien dengan adanya multidiagnosis, pasien dengan gangguan fungsi ginjal atau hati, pasien penerima obat dengan terindeks terapi sempit dan pasien penerima obat yang sering diketahui menyebabkan reaksi obat yang merugikan.

Monitoring efek samping obat perlu dilakukan oleh seorang apoteker dengan maksud untuk memantau setiap respon terhadap obat yang merugikan atau tidak diharapkan yang terjadi pada dosis normal yang digunakan pada manusia untuk tujuan profilaksis, diagnosis dan terapi atau memodifikasi fungsi fisiologis. 


\subsection{Sumber Daya Manusia}

Berdasarkan Permenkes RI No 73 Tahun 2016, Pelayanan Kefarmasian di Apotek diselenggarakan oleh Apoteker, dapat dibantu oleh Apoteker pendamping dan/atau Tenaga Teknis Kefarmasian yang memiliki Surat Tanda Registrasi dan Surat Izin Praktik.

Berikut adalah tabel 4 mengenai sumber daya manusia yang ada di apotik X.

Tabel 4. Sumber Daya Manusia

\begin{tabular}{|c|l|c|c|}
\hline NO & \multicolumn{1}{|c|}{ KETERANGAN } & YA & TIDAK \\
\hline 1 & $\begin{array}{l}\text { Apoteker, Apoteker pendamping dan Tenaga Teknis } \\
\text { Kefarmasian telah memenuhi kriteria persyaratan } \\
\text { administrasi sesuai dengan aturan perundang - undangan }\end{array}$ & $\mathrm{v}$ & \\
\hline 2 & Menggunakan atribut praktik & & $\mathrm{V}$ \\
\hline 3 & Mengikuti pendidikan berkelanjutan & $\mathrm{V}$ & \\
\hline 4 & $\begin{array}{l}\text { Apoteker mampu mengidentifikasi kebutuhan akan } \\
\text { pengembangan diri }\end{array}$ & $\mathrm{v}$ & \\
\hline 5 & $\begin{array}{l}\text { Apoteker, Apoteker pendamping dan Tenaga Teknis } \\
\text { Kefarmasian patuh terhadap aturan perundang-undangan, } \\
\text { sumpah apoteker, standar profesi yang berlaku }\end{array}$ & $\mathrm{v}$ & \\
\hline
\end{tabular}

Berdasarkan hasil penelitian di atas terlihat bahwa untuk sumber daya manusia yang berada di apotik X hampir sudah memenuhi kriteria yang disebutkan dalam Permenkes RI No 73 Tahun 2016, namun di dalam pelaksanaannya sumber daya manusia tidak menggunakan atribut praktik. Atribut praktik penting digunakan pada saat kegiatan kefarmasian di apotek supaya pasien lebih percaya kepada petugas ketika petugas Apotek itu menggunakan seragam praktik dan tanda pengenal. Atribut praktik juga akan meningkatkan citra petugas apotek dimata pasien.

\subsection{Sarana Dan Prasarana}

Berdasarkan Permenkes RI No 73 Tahun 2016, Apotek harus mudah diakses oleh masyarakat. Sarana dan Prasarana Apotek dapat menjamin mutu sediaan farmasi, alat kesehatan dan bahan medis habis pakai serta kelancaran praktik kefarmasiaan. Berikut adalah tabel 5 yang merupakan sarana dan prasarana yang berada di Apotik X di Kota Bandung.

Tabel 5. Sarana Dan Prasarana

\begin{tabular}{|c|l|c|c|}
\hline NO & \multicolumn{1}{|c|}{ KETERANGAN } & YA & TIDAK \\
\hline 1 & Terdapat Ruang Penerimaan Resep & $\mathrm{V}$ & \\
\hline 2 & Terdapat ruang pelayanan resep dan peracikan & $\mathrm{V}$ & \\
\hline 3 & Terdapat ruang penyerahan obat & $\mathrm{V}$ & \\
\hline 4 & Terdapat ruang konseling & & $\mathrm{V}$ \\
\hline 5 & $\begin{array}{l}\text { Terdapat ruang penyimpanan sediaan farmasi, alat } \\
\text { kesehatan dan bahan medis habis pakai }\end{array}$ & $\mathrm{V}$ & \\
\hline 6 & Terdapat ruang arsip & & $\mathrm{V}$ \\
\hline
\end{tabular}

Berdasarkan hasil penelitian di atas masih terdapat sarana dan prasarana yang belum tersedia di Apotik X yaitu ruang konseling dan ruang arsip. Ruang konseling sangat dibutuhkan untuk proses pelayanan kefarmasian klinik yaitu untuk kegiatan konseling. Dengan adanya ruang konseling privasi klien dalam melakukan proses konseling lebih terjaga. Keberadaan ruang arsip juga sangat diperlukan untuk menyimpan dokumen - dokumen supaya lebih tertata rapih dan tersimpan dengan baik dokumen dokumen yang dimiliki oleh Apotik sehingga jika memiliki ruang arsip apabila mencari suatu dokumen akan lebih cepat menemukan dokumen tersebut.

Menurut Permenkes RI No 73 Tahun 2016, ruang konseling sekurang-kurangnya memiliki satu set meja dan kursi konseling, lemari buku, buku-buku referensi, leaflet, poster, alat bantu konseling, buku catatan konseling dan formulir catatan pengobatan pasien. Kemudian untuk ruang arsip dibutuhkan untuk menyimpan dokumen yang berkaitan dengan pengelolaan Sediaan Farmasi, Alat Kesehatan, dan Bahan Medis Habis Pakai serta Pelayanan Kefarmasian dalam jangka waktu tertentu. 


\section{KESIMPULAN}

Standar Pelayanan Kefarmasian yang ada di Apotik X Kota Bandung belum semua nya menerapkan standar pelayanan kefarmasian berdasarkan peraturan perundang-undangan yang berlaku. Standar Pelayanan Kefarmasian Pada kegiatan pengelolaan sediaan farmasi, alat kesehatan dan bahan medis habis pakai belum dilakukan pemusnahan resep setiap 5 tahun. Pelayanan farmasi klinis pada pengkajian resep tidak dilakukan pertimbangan klinis terkait reaksi obat yang tidak diinginkan, kontraindikasi dan pertimbangan klinis terkait interaksi. Pelayanan informasi obat terkait informasi interaksi obat dan informasi farmakokinetik juga belum dilakukan. Pada kegiatan konselin tidak dilakukan konseling yang terdokumentasi. Pelayanan kefarmasian di rumah, Pemantauan Terapi Obat dan Monitoring Efek Samping Obat tidak dilakukan.

\section{DAFTAR PUSTAKA}

Charles J.P. Siregar. 2003. Farmasi Rumah Sakit Teori \& Penerapan. Jakarta: EGC

Satibi dkk. 2018. Manajemen Apotek. Yogyakarta: Gajah Mada University Press.

Sari Prabandari. 2018. Gambaran Manajemen Standar Pelayanan Kefarmasian Di Apotek Permata Kota Tegal. Jurnal Para Pemikir Vol. 7, Nomor 1, 2018: 202 - 208

Undang - Undang Nomor 36 Tahun 2009 Tentang Kesehatan (Lembaran Negara Republik Indonesia Tahun 2009 Nomor 144)

Peraturan Menteri Kesehatan Nomor 9 Tahun 2017 Tentang Apotek (Berita Negara Republik Indonesia Tahun 2017 Nomor 276)

Peraturan Menteri Kesehatan Nomor 73 Tahun 2016 Tentang Standar Pelayanan Kefarmasian Di Apotek (Berita Negara Republik Indonesia Tahun 2017 Nomor 50).

Peraturan Pemerintah Republik Indonesia Nomor 51 Tahun 2009 Tentang Pekerjaan Kefarmasian (Lembaran Negara Republik Indonesia Tahun 2009 Nomor 124). 